technical assistanco in locust control and had accepted some responsibility for equipping and financing the new Eastern African Organization in its early years.

\section{Medical Research in the United States}

As a pre-requisite in nearly cvery aspect of medical and biological study, basic research has always received emphasis in the several programmes of the National Institutes of Health. In recent years, however, the importance of fundamental research has grown tremendously. This has arisen following the definition of new disease conditions, the development of new drugs and other now forms of therapy and new modical and biological discoveries on a broad scale which in turn have revealed previously unexplored areas which scientists must now study. Tho research carried out and supported by the National Institutes of Health is oriented toward specific disease conditions, such as cancer, arthritis and heart ailments. By contrast, the Division of General Medical Sciences supports fundamental research which is not necessarily directed toward specific diseases, but toward a better understanding of the body's structure and function as revealed by research in the sciences basic to medicine and biology. The Division also supports research in certain pre-clinical and clinical fields and in the effocts of man's environment on his health. Such research is crucial in nearly all medical investigations and, therefore, plays an important part in determining the ultimate success of applied medicine. The greater part of the basic research supported by the Division may be classified under the headings of developmental biology and the chemistry of life processes. The other main areas supported by the Division are environmental factors in health and disease; public hoalth, medical care and nursing; clinical scionoos; and methods and tools of science. The work in each of these sections, as well as that in the Centre for Ageing Research, is described in a booklet, Division of General Medical Science, obtainablo from the U.S. Government Printing Office, Washington, D.C. (Public Health Service Publication, No. 757).

\section{Science. Progress}

A ReChin issue of Science Progress (vol. 50, No. 200 ; October 1962. 15s.) includes a paper by Dr. A. E. A. Werner on seientific methods used in the examination and conservation of antiques -a subject of increasing importance in museums. Other papers include "On Inertial Reference Frames", by Dr. H. Dingle, and "Plant Nematodes", by Mr. F. G. W. Jonos. Recent advances in astronomy, physics, general and physical chemistry, geology, biochemistry and plant physiology are dealt with by various authorities, and the issue concludes with a large number of book reviews.

\section{Japanese Journal of Applied Physics}

Thw first issue-July 1962-of the Japantese Journal of Applied Physics, to be published monthly with the co-operation of the Physical Society of Japan and the Japan Society of Applied Physics, includes oight original papers and four short notes (Japanese Journal of Applied Physics, Vol. 1, No. 1; July 1962. 1'p. 1-70. Subscription rate: annual, 10 dollars; singlo copy, 1 dollar. Bunkyo-ku, Tokyo: Faculty of Science, University of Tokyo, 1962). 'The papors doal with vibrational spectra of ruby and hematite in the infra-rod region; ammonia maser standard I; piezoelectric properties of triglycine sulphate; epitaxial vapour growth of single crystal Ga; dynatron-type negative resistance observed in the collector voltagesaturation region of the friction transistor; induced radioactivity in iron by high-energy protons; study of field emission cathode by fiold ion microscopy; and a new apparatus for measuring dynamic viscoelastic properties of polymers.

\section{Bibliography of Electronics}

A RECENTLY published guido provides, under 67 main hoadings, more than 3,300 references to the more important text-books, papers and other publications in the field of electronics (Electronics: a Bibliographical Guide. By C. K. Moore and K. J. Spencer. Pp. xvii +411 . London: Maedonald and Co. (Publishers), Ltd., 1961. 65s. not). For the purposes of their work the authors have interpreted olectronics as the "science and technology based on the use of electron tubes and semiconductors", inchuding both infra-red and ultra-sonic techniques. The first and longest section, divided into $13 \mathrm{sub}-$ sections, provides 274 references to other bibliographies, poriodicals and publications of a general nature, while succeeding sections deal with specific subjects ranging from electron microscopy to radio astronomy. Approximately half the number of references in each subject are to important papers and reviews, and half to text-books, symposia proceedings and bibliographies.

The main period covered is $1945-59$, but several earlier references to pioneer work in each field are included, and an addendum covers significant advances during 1960. Author and subject indexes are providod. The author's are to bo congratulated on this valuable and comprohensive volume, and we may hope that they will find it possible to provide revisions or furthor addenda in future years.

\section{British Inter-Regional Library Coverage Scheme}

THE Library Association Record for September 1962 $(64$, No. 9) includes the annual roport for 1961 of the National Committee on Regional Library Co-operation. The Inter-Regional Coverage Scheme, which came into operation on January 1,1959 , is working out satisfactorily, and requests for British books published since 1959 now go direct from region to region and not through the National Central Library. Improvement of the coverage of periodicals is now in the hands of the regions, and, with the publication of the British Technology Index, it is hopod that in 1963 all regions will bo able to accommodate requests for the 400 titles covered. All regions in England were connected by telex by the end of the year, and its installation is also being considered by the Scottish Contral Library. It is hoped to bring fully into operation by April 1963 a book-store at Woolwich Arsenal capable of holding 500,000 volumes, thus enabling the National Central Library to accept considerably more donations from the regions and caso their space problems.

Macmillan and Co., Ltd.: Cleaver-Hume Press, L.td.

Some time ago, Cloaver-Hume Press, Ltd., found that it would soon become difficult to deal, in the present premises, with its expanding business. This lod to discussions with Macmillan and Co., Ltd., because it was felt that their now warchouse, to be built at Basingstoke, might help resolve this problem. As a result, co-operation between the two companies has gone much farther. 